\title{
Estimulación audiovisual en niños con necesidades especiales, para obtener el hábito de higiene oral
}

\section{Audiovisual stimulation in children with special needs, for the oral hygiene habit}

\author{
César Cayo", Cristian Escurra ${ }^{* *}$ Percy Bayona ${ }^{* * *}$, Karem Torres ${ }^{* * *}$
}

http://dx.doi.org/10.21503/CienciayDesarrollo.2012.v15i2.01

\section{RESUMEN}

La presente investigación tiene por objeto determinar la eficacia de la estimulación audiovisual para formar el hábito de higiene bucal, en los escolares con diversas tipos de necesidades especiales en el Colegio Básico Especial No 04 Santa Rosa de los Huacos, de Hualmay. Se trabajó con un total de 28 alumnos, utilizando el método de estimulación audiovisual. Se tomó un test de entrada a la profesora de aula, para conocer los hábitos de higiene oral de cada niño . Luego se procedió a proporcionar cepillos y pasta dental; además, se les proporcionó un disco compacto con música adaptada, para que los niños la escuchen después de ingerir sus alimentos por un mes. Además, dos veces a la semana se realizaba una teatralización y coreografía que sensibilizaba a los niños y profesores para la higiene oral. La forma en que se verificó la obtención de los resultados fue observacional, con apoyo de una cámara filmadora o por inspección directa. Se utilizaron estadísticos de contraste de la prueba de McNemar para la significación de los cambios, utilizando la distribución binomial. Se observó al final del mes, que los 28 niños se higienizaban la cavidad oral de forma voluntaria al hacerles escuchar la música con la letra adaptada, a pesar de que al inicio solo se cepillaban 19 niños esporádicamente, mientras los otros nueve solo lo hacían cuando eran obligados. Se concluyó que la estimulación audiovisual induce de forma eficaz a los niños con necesidades especiales a obtener el hábito de higiene oral.

Palabras clave: estimulación audiovisual, necesidades especiales, hábito de higiene oral.

\section{ABSTRAC}

Aims. To determine the effectiveness of audio-visual stimulation to train the habit of oral hygiene in school children with different types of special needs in special basic school "Santa Rosa de los Huacos $N^{o}$ 4 " in Hualmay. Material and methods. We worked with a total of 28 students using the method of audiovisual stimulation. It took an entrance test to the classroom teacher, to know the oral hygiene habits of each child then we proceeded to provide toothbrushes and toothpaste, and it was given them a CD with adapted music so that children hear after eating their food for a month. Also twice a week it was per-

\footnotetext{
* Docente de la Escuela Académico-Profesional de Estomatología y Obstetricia de la Facultad de Medicina Humana y Ciencias de la Salud de la UAP, Sede Huacho. E-mail: cesarcayorojas@hotmail.com

** Docente de la Escuela Académico-Profesional de Estomatología y Enfermería de la Facultad de Medicina Humana y Ciencias de la Salud de la UAP, Sede- Huacho. E-mail: crivan16@hotmail.com

*** Alumno del VIII ciclo de la Escuela Académico-Profesional deaEstomatología de la Facultad de Medicina Humana y Ciencias de la Salud de la UAP, filial Huacho. E-mail: pandreeb@live.com

**** Alumna del VII ciclo de la Escuela Académico-Profesional de Estomatología de la Facultad de Medicina Humana y Ciencias de la Salud de la UAP, Sede Huacho. E-mail: karemnita29@hotmail.com
} 
formed a theatrical choreography that sensitized to oral hygiene to children and teachers. It was verified by observational results which were supported by a video camera or by direct inspection in which we used the statistics test of McNemar for the importance of changes, using the binomial distribution. Results. It was noted at the end of the month, that 28 children brushed their teeth voluntarily to make them listen to music with adapted lyrics, despite early only 19 children brushed sporadically and the other 9 just did it when they were forced to do it. Conclusions. Audio-visual stimulation induces effectively to children with special needs to get into the oral hygiene habit.

Key words: audiovisual stimulation, special needs, oral hygiene habit.

\section{INTRODUCCIÓN}

Dentro de los antecedentes relacionados con el trabajo de investigación, se tomaron en consideración los trabajos realizados por:

Albertson, afirmó que un programa preventivo para los niños incapacitados debe ser enseñado a los padres, enfermeras y otras personas dedicadas a la atención diaria del niño ${ }^{1}$.

Y.c. Torres, publicó una investigación sobre incidencia y prevalencia de la enfermedad gingival en niños con síndrome de Down. Evaluó 52 niños de ambos sexos en edad de 16 a 19 años, en el Centro Piloto de Parálisis Cerebral de Mongolismo "Acuarius" y el Instituto para Niños Excepcionales No 6 de Lima. Los resultados indicaron que $8,46 \%$ tuvo inflamación gingival. La prevalencia y severidad de la gingivitis en la zona anterior y posterior fue similar, a la predominancia en el maxilar inferior. Concluye que el factor etiológico principal del problema inflamatorio fue la pobre higiene dental acondicionada por la deficiencia mental ${ }^{2}$.

R. Viteri, en la tesis que sustentó tenía el propósito de comprobar la eficiencia de un modelo educativo para la salud oral desarrollado y experimentado en pequeños grupos por el Dpto. de Odontología Social de la Universidad Peruana Cayetano Heredia y su repercusión en las condiciones clínicas periodontales. El autor concluye que "la aplicabilidad del módulo de instrucción en autoprofilaxis en un C.E. rural es efectiva y representa una alternativa más a considerar en los programas de salud oral" ${ }^{3}$.

J. Thornton realizó un estudio en una institución para pacientes con retardo mental. Compararon los niveles de higiene oral con la prevalencia de enfermedad periodontal. El resultado fue un elevado nivel de placa bacteriana y enfermedad periodontal ${ }^{4}$.

Russel, en su trabajo tuvo como objetivos verificar las condiciones de higiene bucal de pacientes portadores de deficiencia mental de nivel educable y no educable y evaluar la eficacia de un programa preventivo educativo dirigido a pacientes especiales, con la participación de los padres y sus responsables ${ }^{5}$.

L. M. Arch (et al), realizó una encuesta a 122 padres de niños especiales, donde solo respondieron un $70 \%$ de ellos, de los cuales se obtuvo que un $94 \%$ de los padres desearían que se realizara un programa preventivo sobre salud bucal y se brindara mayor información sobre salud bucal, dieta, higiene bucal para sus hijos, y también destacan la necesidad del tratamiento odontológico sin discriminación para sus hijos ${ }^{6}$.

L. Galarza, evaluó la efectividad de un sistema multimedia en la educación bucal. La muestra fue de 384 pacientes adultos; consignó este trabajo en razón de que los aspectos motivacionales (técnicas audiovisuales, son válidos para todo 
grupo etáreo de la población. Entre las variables se considera el grado de instrucción, medido con la siguiente escala: inadecuado, regular y adecuado. También se evaluó el nivel de conocimiento de los pacientes en salud oral y el sexo. Concluyó que: el nivel de conocimiento después de la intervención educativa se incrementó de $14 \%$ (52) a $70 \%$ (272) en el nivel de conocimiento adecuado, mientras que el nivel de conocimiento inadecuado disminuye notablemente de $24 \%$ (94) a $4 \%$ ". En relación con el sexo, se determinó que las mujeres alcanzaron un mejor nivel de conocimiento en el área de especialidades; además, añade que: "el sistema multimedia para la educación es uno de los recursos disponibles para todos a fin de incrementar y/o modificar conocimientos y/o falsos conceptos que favorezcan la conducta a tomar por las personas adultas"7.

Cabellos, relacionó el nivel de conocimiento sobre higiene bucal de los padres de niños con necesidades especiales y evaluó la higiene bucal de estos mismos niños en el Centro Ann Sullivan del Perú. La muestra fue de 90 padres y sus respectivos hijos con necesidades especiales (síndrome de Down, retardo mental, autismo). En la primera fase de la investigación, evaluó el nivel de conocimiento sobre higiene bucal en los padres, para lo cual utilizó como instrumento un cuestionario de 12 preguntas, dividido en cuatro partes: tres preguntas sobre elementos de higiene bucal, tres preguntas sobre hábitos de higiene bucal, tres preguntas sobre patología bucal relacionada con higiene bucal y tres preguntas sobre técnicas de higiene bucal. En la segunda fase de la investigación se evaluó el índice de higiene oral de los niños con necesidades especiales. Los resultados obtenidos en la investigación determinaron un regular nivel de conocimiento en los padres, con un $68,9 \%$, en tanto que el índice de higiene oral encontrado en los niños fue malo, con un $88,9 \%$, estableciéndose una relación estadísticamente significativa entre el IHO de los niños y el nivel de conocimiento de los padres, con un $\mathrm{p}<0,05$ y una correlación in- versa regular, $\mathrm{p}=-0,58$ y con un $\mathrm{p}<0,05$, es decir, un nivel de conocimiento regular en los padres relacionado con un IHO malo en los niños ${ }^{8}$.

Como vemos, hay diversos estudios realizados en el campo de la prevención con el objetivo común de cuidar la salud oral de diversos factores como la placa bacteriana, problemas gingivales y la caries dental en diferentes clases de personas, incluido aquellos que presentan problemas de necesidades especiales.

La placa bacteriana es una película gelatinosa que se adhiere firmemente a los dientes y superficies blandas de la cavidad oral. Está formada principalmente por colonias de bacterias (60\%-70 $\%)$, agua, células epiteliales descamadas, leucocitos y restos alimenticios. Es el factor etiológico determinante para la caries y la enfermedad periodontal. En la actualidad se piensa que la patogenicidad de la placa bacteriana depende de su composición cualitativa, lo que se conoce como teoría específica. Según esta teoría, no todas las placas bacterianas presentan igual potencial para producir caries o enfermedad periodontal, sino que varían dentro de cada hábitat bucal e incluso dentro de un mismo individuo. Inmediatamente después de las comidas es cuando el poder acidógeno del metabolismo de la placa es mayor ${ }^{1}$.

La enfermedad periodontal es una enfermedad que afecta a las encías y a la estructura de soporte de los dientes. La bacteria presente en la placa causa la enfermedad periodontal. Si no se retira, cuidadosamente, todos los días con el cepillo y el hilo dental, la placa se endurece y se convierte en una substancia dura y porosa llamada cálculo (también conocida como sarro).

La caries es una enfermedad multifactorial que se caracteriza por la destrucción de los tejidos del diente como consecuencia de la desmineralización provocada por los ácidos que genera la placa bacteriana a partir de los restos de alimentos, que 
se exponen a las bacterias que fabrican ese ácido a partir de la dieta ${ }^{6}$.

Es por el conocimiento de estos factores que repercuten de manera negativa en la salud oral, que nos dimos la tarea de realizar este trabajo de investigación, con el propósito de demostrar que sí es posible sensibilizar a los niños con necesidades especiales a un constante cepillado mediante la estimulación audiovisual.

Es menester que mediante ciertos tipos de estimulación, en este caso la audiovisual, se motive al aprendizaje cognitivo de un niño con necesidades especiales, modificando con esto sus hábitos de higiene oral, a fin de lograr una acumulación de placa bacteriana mínima y así mitigar los diferentes problemas periodontales como consecuencia de un poco o nada practicado hábito de higiene. Por lo tanto, la importancia de nuestro trabajo de campo radica en que los niños adquieran el hábito de higienizarse la cavidad oral de forma voluntaria. Es por estas razones que nos planteamos el siguiente problema; ¿se podrá formar el hábito de higienizarse la cavidad oral de forma voluntaria en los niños con necesidades especiales, utilizando la estimulación audiovisual?

La hipótesis principal planteada es: a mayor estimulación audiovisual, mayor influencia en la disposición de los niños con necesidades especiales a higienizarse la cavidad oral. Las hipótesis derivadas son tres: 1) Mediante la estimulación audible se consigue habituar a los niños del"Colegio Básico Especial No 04 Santa Rosa de los Huacos, "a un cepillado diario con su pasta dental. 2) Mediante la estimulación visual se consigue habituar a los niños del "Colegio Básico Especial No 04 Santa Rosa de los Huacos", a un cepillado diario con su pasta dental. 3) Mediante una representación teatral adecuada se logra sensibilizar a los alumnos con necesidades especiales y sus profesores a prevenir la caries con mayor higiene bucal.
Como objetivo principal se planteó determinar la eficacia de la estimulación audiovisual para formar el hábito de higiene bucal, en los escolares con diversos tipos de discapacidades mentales del Colegio Básico Especial No 04 Santa Rosa de los Huacos, de Hualmay, a través de tres objetivos específicos: 1) estimular en forma audiovisual el cepillado dental a los escolares, 2) estimular mediante una representación teatral el cuidado de la higiene oral en los escolares, 3) incrementar el número de estudiantes a una participación voluntaria al cepillado dental.

Dentro de las limitaciones estuvieron la poca existencia de antecedentes de investigación similares relacionados con la estimulación audiovisual en niños con discapacidad mental en el campo estomatológico. Otra dificultad fue que no se contaron con más alumnos como muestra, puesto que los demás (alumnos no considerados en el programa) no asistían regularmente.

\section{MATERIAL Y MÉTODOS}

El tipo de estudio fue experimental y longitudinal. La aplicación de este método se realizó en 28 niños, teniendo como criterio de inclusión a aquellos con necesidades especiales leves o moderadas que ya venían asistiendo de forma regular a clase y que contaban con el consentimiento de sus padres para realizar este trabajo, y que se encontraran entre 4 y 15 años de edad. Fueron excluidos del estudio aquellos niños que presentaban necesidades especiales de moderado a severo. El trabajo se realizó durante el mes de octubre del año 2011.

Se tomó un test de entrada a la profesora de aula, para conocer el hábito de higiene oral de cada niño. Luego se procedió a proporcionar a los niños cepillos y pasta dental, ambos de marca Colgate. Además, se les proporcionó un disco compacto con una música adaptada, para que la escuchen después de ingerir sus alimentos, por 
un mes. Cabe resaltar que cada aula ya contaba con un equipo propio de sonido, y además, una vez a la semana se realizaba una teatralización con un guión creado por los alumnos, el mismo que permitía de forma sencilla que el observador se diera cuenta de que el cepillo y la pasta dental juntos combatían o eliminaban la caries; también se preparó una coreografía bailada al ritmo de la música con la letra adaptada. En este baile se utilizaba el cepillo para demostrar cómo se deben cepillar los niño. Estos, a su vez, bailaban imitando el paso de los estudiantes de estomatología.

La verificación de los resultados se hizo con apoyo de una cámara filmadora y a través de un test final de preguntas dicotómicas con claves, a la profesora de aula.

A continuación se detallan paso a paso los procedimientos.

Se inició el trabajo de investigación con permiso de la directora de la Institución Educativa Básica Especial Santa Rosa de los Huacos, Hualmay.

$\mathrm{Al}$ aplicar violeta de genciana, se demostró a los presentes la cantidad de placa bacteriana que presentaban los dientes de sus alumnos por no tener el hábito de higiene oral adecuado debido a la poca disposición de los alumnos para cepillarse los dientes.

Luego de haber mostrado la cantidad de placa bacteriana que presentaban los niños, se procedió a realizar la charla educativa a las profesoras. Luego se hizo el reparto del disco compacto con la letra de la música adaptada, además de cepillos y pastas dentales (estos dos últimos de marca Colgate, que se obtuvieron por donación de la empresa, previa solicitud) por parte de los alumnos de la UAP.

Finalmente, se procedió a evaluar con un test a las profesoras de los 28 alumnos escogidos de forma no probabilística, por conveniencia (puesto que solo ellos reunían los requisitos de los criterios de inclusión y exclusión), para saber la disposición voluntaria de los niños al cepillado y además evaluar si se entendió bien el tema.

$\mathrm{Al}$ analizar el test se descubrió que todos habían entendido bien el proceso y su parte en el proyecto, y además se puso en conocimiento lo siguiente: que 19 alumnos rara vez se cepillaban de manera voluntaria, y 9 alumnos nunca lo hacían de manera voluntaria.

Ese mismo día se presentó, una obra teatral denominada "Una sonrisa sana".

En dicha teatralización se intentó dar a entender a los niños que es importante la higiene oral, con la finalidad de que estos hechos visuales quedaran grabados en su memoria y así pudieran evocar de manera inducida la importancia del cepillado dental.

Siempre se transmitía el mensaje a los niños delante de sus profesores, para que estos les pudieran recordar en clase: "qué pasaba si no se cepillaban los dientes".

Se presentó un baile cepillándose los dientes y la lengua con la música adaptada, a fin de estimular a los niños de dicha institución educativa para higienizarse la cavidad oral. La música se reproducía con un equipo de sonido proporcionado por la institución educativa utilizando los parlantes colocados en el patio. La música seleccionada para la adaptación, con una letra que estimulaba al cepillado dental, era La Diente Cumbia (adaptación de La Terecumbia de Tommy Portugal y su Grupo Pasión).

Una de las constataciones que surgieron al trabajar con niños en diferentes niveles de necesidades especiales, después de varias sesiones de estimulación, fue que los niños iban adquiriendo paula- 
tinamente el hábito de higiene oral gracias tanto al grupo a cargo del proyecto como al apoyo por parte del personal docente de dicho centro educativo.

$\mathrm{Al}$ iniciar el último día de nuestras labores de campo, instalada la música y previa presentación teatral, los niños empezaban a cepillarse los dientes de manera voluntaria en un $100 \%$ del total muestreado, sin el apoyo del personal docente de la institución.

La recolección de los datos se hizo por observación directa (también se filmaba para registrar y constatar). Además, las fotos se centraron en los alumnos que se cepillaban poco o nada de forma voluntaria, según el test recolectado de las profesoras.

\section{RESULTADOS}

En el aula "Padre Pascual Uva", se encontró un total de cinco alumnos participantes, de los cuales solo tres de ellos se cepillaban esporádicamente de manera voluntaria y sin ayuda antes de la estimulación. Posteriormente a la estimulación, se observó que los dos niños que no se cepillaban de manera voluntaria, lo empezaron a hacer.

En el aula "Virgen María", la población total era de diez alumnos, de los cuales solo siete se cepillaban de manera voluntaria antes de iniciar la estimulación audiovisual. Posteriormente, los tres alumnos restantes empezaron a cepillarse, observándose que la población total de dicha aula empezó a cepillarse de manera voluntaria y sin ayuda.

En el aula "Niño Jesús", la cantidad total de alumnos eran cinco, pero solo tres de ellos se cepillaban de manera voluntaria y sin ayuda. El resto no lo hacía. Después de haberlos estimulado de manera audiovisual, se observó la mejora debido a que estos dos alumnos empezaron a cepillarse de manera voluntaria.
En el aula "Amiguitos de Santa Rosa de Lima", la población total participante era de ocho alumnos. Solo seis de ellos se cepillaban esporádicamente de manera voluntaria. Después de la estimulación, se observó que los dos alumnos restantes que no lo hacían de manera voluntaria, empezaron a cepillarse de forma voluntaria.

Hipótesis de nulidad.

Ho: Para cualquier niño después de la estimulación audiovisual, la probabilidad de que desplace su intención de no cepillarse a cepillarse $\left(\mathrm{P}_{\mathrm{A}}\right)$ es igual a la probabilidad de que cambie su intención de cepillarse a no cepillarse $\left(\mathrm{P}_{\mathrm{D}}\right)$, esto es:

Ho: $\mathrm{P}_{\mathrm{A}}=\mathrm{P}_{\mathrm{D}}=1 / 2$

H1: $\mathrm{P}_{\mathrm{A}}>\mathrm{P}_{\mathrm{D}}$

Prueba estadística: Se escoge la prueba de McNemar para la significación de los cambios, porque usa dos muestras relacionadas. Es del tipo ante-después y usa medición nominal. (clasificatoria).

\section{Tabla 1. Clasificación de la prueba de McNemar para la significación de los cambios.}

\begin{tabular}{cccc} 
& & \multicolumn{2}{c}{ DESPUÉS } \\
& & Sí & No \\
\multirow{3}{*}{ ANTES } & No & A & B \\
& Sí & C & D \\
\hline
\end{tabular}

Nivel de significación. Sean $\alpha=0,05$ y $\mathrm{N}=$ 28 , número de niños observados antes y después de la estimulación audiovisual.

1. Distribución muestral. En la tabla de valores críticos de chi cuadrado para diferentes niveles de significación, la distribución muestral $\mathrm{X}^{2}$ calculada con fórmula se aproxima fuertemente a la distribución chi cuadrado con $\mathrm{gl}=1$.

2. Región de rechazo. Ya que $H_{1}$ predice 
la dirección de la diferencia, la región de rechazo es de una cola. La región de rechazo está compuesta por todos los valores de $\mathrm{X}^{2}$ (calculada con datos en los que A $>$ D) tan grandes que tiene una probabilidad de una cola asociada con su ocurrencia conforme $\mathrm{H}_{\mathrm{o}}$ de 0,05 o menos.

3. Decisión. Según el modelo de prueba. A y $\mathrm{D}$ son los niños que cambiaron de no cepillarse a cepillarse y de cepillarse a no cepillarse, respectivamente. B y C representan a los niños que no cambiaron y estuvieron en la misma categoría en ambas ocasiones. Nosotros estamos interesados en los niños que mostraron cambio, es decir, en aquellos representados en las celdas A y D.

Tabla 2. Número de niños que se cepillaron antes y después de la estimulación audiovisual.

\begin{tabular}{cccc} 
& & \multicolumn{2}{c}{ DESPUÉS } \\
& & Sí & No \\
\multirow{3}{*}{ ANTES } & No & 9 & 0 \\
& Sí & 19 & 0 \\
\hline
\end{tabular}

$\mathrm{X}^{2}=\left[(|\mathrm{A}-\mathrm{D}|-1)^{2}\right] /(\mathrm{A}+\mathrm{D})$

$\mathrm{X}^{2}=\left[(|9-0|-1)^{2}\right] /(9+0)$

$\mathrm{X}^{2}=7,11$

Tomando en consideración que las frecuencias esperadas son pequeñas, es decir: $(\mathrm{A}+\mathrm{D}) / 2=(9+0) / 2=4,5$ (menor que 5$)$, deberá usarse la distribución binomial antes de la prueba McNemar. En el caso binomial, $\mathrm{N}=\mathrm{A}+\mathrm{D}$, y x es la menor de las dos frecuencias observadas, A o D:

$$
\mathrm{N}=9+0 \quad \mathrm{y} \quad \mathrm{X}=0
$$

Usando la tabla de probabilidades asociadas con valores tan pequeños como los valores observados de $\mathrm{X}$ en la prueba binomial, para una cola tenemos que $p=0,002$.

Tabla 3. Estadísticos de contraste de la prueba de McNemar para la significación de los cambios, utilizando la distribución binomial.

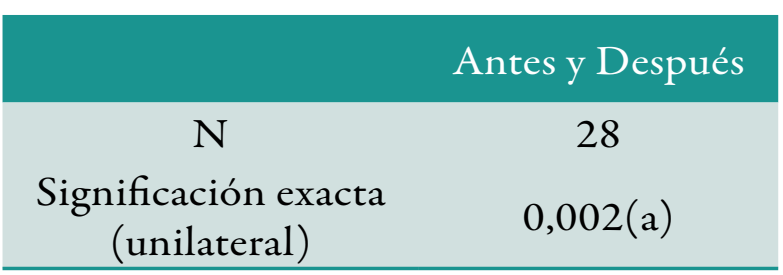

(a) Se ha usado la distribución binomial.

Este valor coincide aproximadamente con el de McNemar. Como la tabla de chi cuadrado revela que $\mathrm{X}^{2} \geq 7,11 \mathrm{y} \mathrm{gl}=1$, la probabilidad de ocurrencia conforme a Ho es $\mathrm{p}<$ 0,025 (el valor de probabilidad dado en la tabla chi cuadrado es dividido en dos porque se requiere una prueba de una cola y la tabla de estos valores da de dos colas).

En vista de que la probabilidad conforme a Ho asociada con la ocurrencia observada es $\mathrm{p}<0,025$, menor que $\alpha=0,05$, el valor observado de $\mathrm{X}^{2}$ está en la región de rechazo, y se rechaza $\mathrm{H}_{\mathrm{o}}$ para aceptar $\mathrm{H}_{1}$.

Puesto que $\mathrm{p}=0,002$ de la tabla para el valor observado es menor que $\alpha=0,05$, se rechaza Ho y se acepta $\mathrm{H} 1$.

\section{DISCUSIÓN}

La aplicabilidad del método de estimulación audiovisual surte efectos considerables en personas con necesidades especiales, tal como se demostró en nuestro trabajo, puesto que de 9 niños con necesidades especiales que no se cepillaban de forma voluntaria, al final del proceso de estimu- 
lación audiovisual, se logró que el 100 \% de los 9 niños se cepillaran por voluntad propia; además, se logró consolidar al cepillado voluntario en 19 niños restantes. Esto hace ver la necesidad de instaurar programas educativos con métodos similares aplicados a la salud oral en todos los colegios, en especial en instituciones que tienen a su cargo niños con necesidades especiales, para promover de esta forma hábitos de higiene oral.

En 1974, Albertson afirmó que un programa preventivo para los niños incapacitados debe ser enseñado a los padres, enfermeras y otras personas dedicadas a la atención diaria del niño, para obtener resultados significativos en la prevención, ${ }^{1}$ como se corroboró en este trabajo. Gracias a la capacitación accesible que se dio a las profesoras de aula, ellas mismas pudieron aplicar el método de estimulación audiovisual todos los días, de lunes a viernes, después de que los niños ingerían sus alimentos. Se obtuvieron resultados positivos con un $95 \%$ de confiabilidad, según la prueba de McNemar.

El presente trabajo contó con el apoyo total de los padres, que brindaron su consentimiento para realizar esta investigación, lo que reafirma que los padres desean que se apliquen programas preventivos odontológicos a sus hijos, sin discriminación. Tal como Arch, L. M.; Jenner, A. M.; Whittle, J. G. en 1994, en una encuesta realizada a 122 padres de niños especiales, donde solo respondió un $70 \%$ de padres, se demostró que un $94 \%$ de los padres desean que se ponga en marcha un programa preventivo sobre salud bucal y se brinde mayor información sobre salud bucal, dieta, higiene bucal para sus hijos, y destacan además la necesidad del tratamiento odontológico sin discriminación para sus hijos ${ }^{6}$. Cabellos, en 2006, observó que el nivel de conocimiento sobre elementos de higiene bucal en padres de niños discapacitados era regular, lo que repercutía en que sus hijos presentaban bajo índice de higiene oral. Se pudo verificar al inicio de nues- tra investigación que los niños presentaban gran cantidad de placa bacteriana, lo que nos permite afirmar que tanto padres como profesores tienen un bajo nivel de conocimiento de la importancia de la higiene bucal ${ }^{8}$. En nuestro estudio se corrobora que un mecanismo audiovisual puede ser utilizado para crear conocimiento y modificar conductas, y en este caso se utilizó con un fin positivo, cual fue el de crear hábitos de higiene en niños con necesidades especiales leves o moderadas, tal como demostró Galarza L. en 1996, utilizando un sistema multimedia como recurso audiovisual ${ }^{7}$. De esta forma se logró elevar la frecuencia del cepillado de manera voluntaria, lo cual demuestra que la estimulación audiovisual los ayudó a obtener el hábito del cepillado diario, utilizando, en vez de un sistema multimedia, la representación teatral y la música con letra adaptada como mensajes motivadores para la higiene oral.

Con todo, se requieren futuros estudios que abarquen mayor tiempo de estimulación audiovisual y que se hagan pruebas específicas para evaluar el índice de higiene oral y el nivel de gingivitis. Por ello, se propone que los estudiantes de estomatología de todo el Perú incluyan en su récord de la asignatura de Odontología Preventiva pruebas de índice de higiene oral, y eduquen a los niños con necesidades especiales a cuidar su salud oral, utilizando métodos como la estimulación audiovisual.

En conclusión, en este trabajo se pudo demostrar que la estimulación audiovisual induce de forma eficaz a los niños con necesidades especiales a obtener el hábito de higiene oral.

\section{AGRADECIMIENTOS}

Queremos agradecer de manera muy especial al Dr. Segundo García Rodríguez por la constante motivación y apoyo que nos brindó para realizar este trabajo, así como también al CD. Javier 
Ramos de los Ríos. Gracias también a todos los alumnos del séptimo ciclo de estomatología de la UAP, filial Huacho, 2012-2, en especial a los alumnos Jonatan Ochoa y Luis Ángel Vargas Arévalo. A este último, por haber creado la letra y entonado la música adaptada que se utilizó en el trabajo realizado. A Colgate por habernos proporcionado los materiales necesarios para realizar este trabajo de investigación.

\section{REFERENCIAS BIBLIOGRÁFICAS}

1. Albertson D. Prevención y el niño incapacitado. Clínica Odontológica Norteamericana. Primera edición. México D.F., Interamericana S.A., 1974.

2. Torres Y. C. Incidencia y prevalencia de enfermedad gingival en niños especiales. El síndrome Down en nuestro medio (tesis para optar el título de cirujano dentista). Lima, Universidad Nacional Mayor de San Marcos, 1976.

3. Viteri R. Repercusión de un método de educación para la salud oral aplicable en centros educativos primarios en zonas rurales de sierra sobre las condiciones clínicas periodontales (tesis para optar el título de cirujano dentista). Lima, Universidad Peruana Cayetano Heredia, 1988.

4. Thorton J. "Oral hygiene levels and periodontal disease prevalence among residents with mental retardation at varuous residential setting”. Spec-Care-Dentist. 1989; 9 (6): 186-90.

5. Russel G. M.; Kinirons, M. J. "The Attitudes and Experience Community. Dental Officers in Northen Ireland in Treating Disabled People”. Community Dent. Health. 1993; (4): 327-333.

6. Arch L. M., Jenner A. M., Whittle J.G. "The Views and Expectations Regarding Dental Care of the Parents of Children with Special Dental Needs: A Survey". Saúde Bucal par. 1994; 1(1/2): 123-32.
7. Galarza L. Efectividad del sistema multimedia en la motivación y educación del paciente (tesis de bachiller). Lima, Universidad San Martín de Porres, 1996.

8. Cabellos D. Relación entre el nivel de conocimiento sobre higiene bucal de los padres y la higiene bucal del niño discapacitado en el Centro Ann Sullivan del Perú (tesis para optar el título de cirujano dentista). Lima, Universidad Nacional Mayor de San Marcos, 2006. 


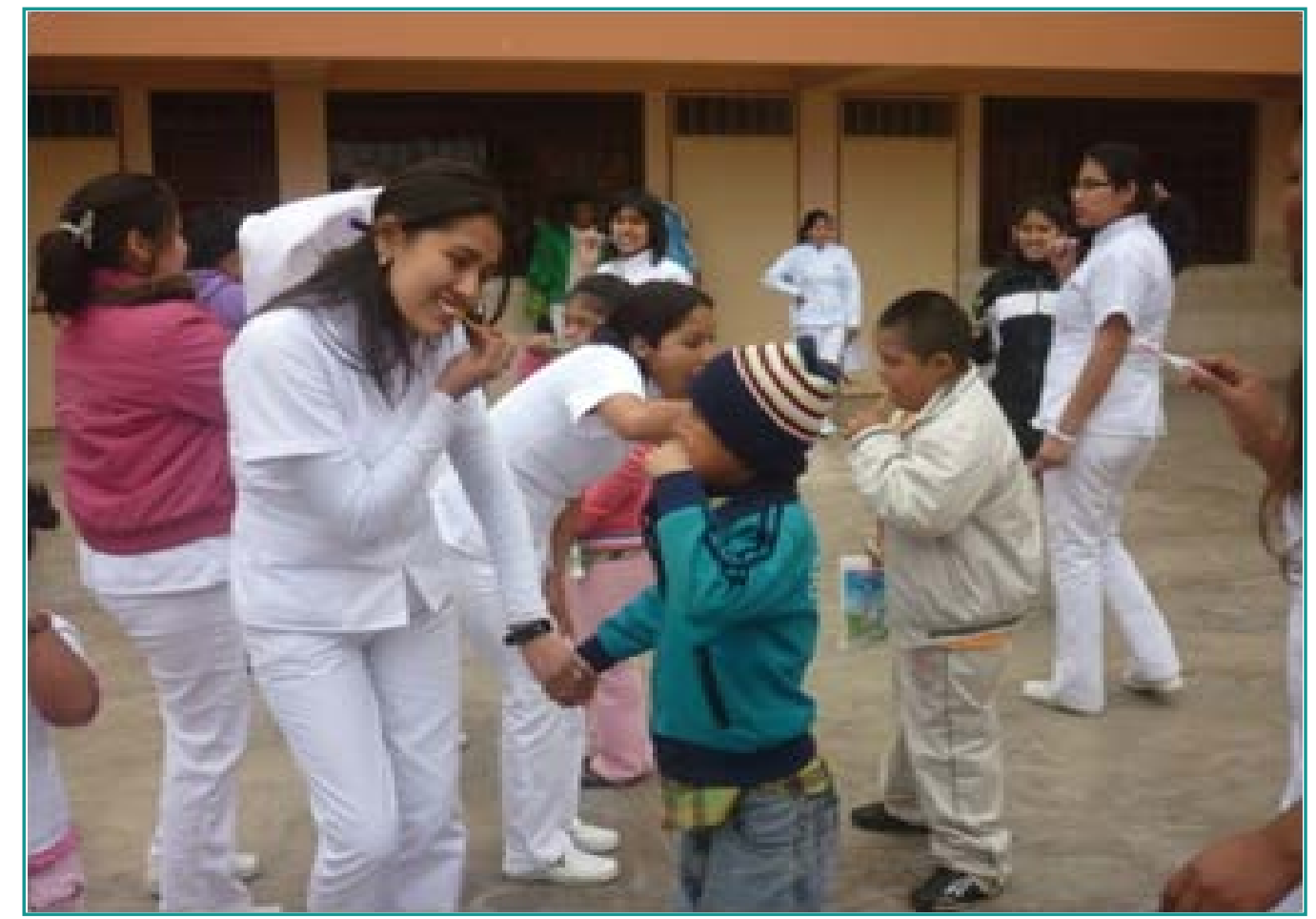

Fotografía 1. Baile interactivo con los alumnos del centro educativo.

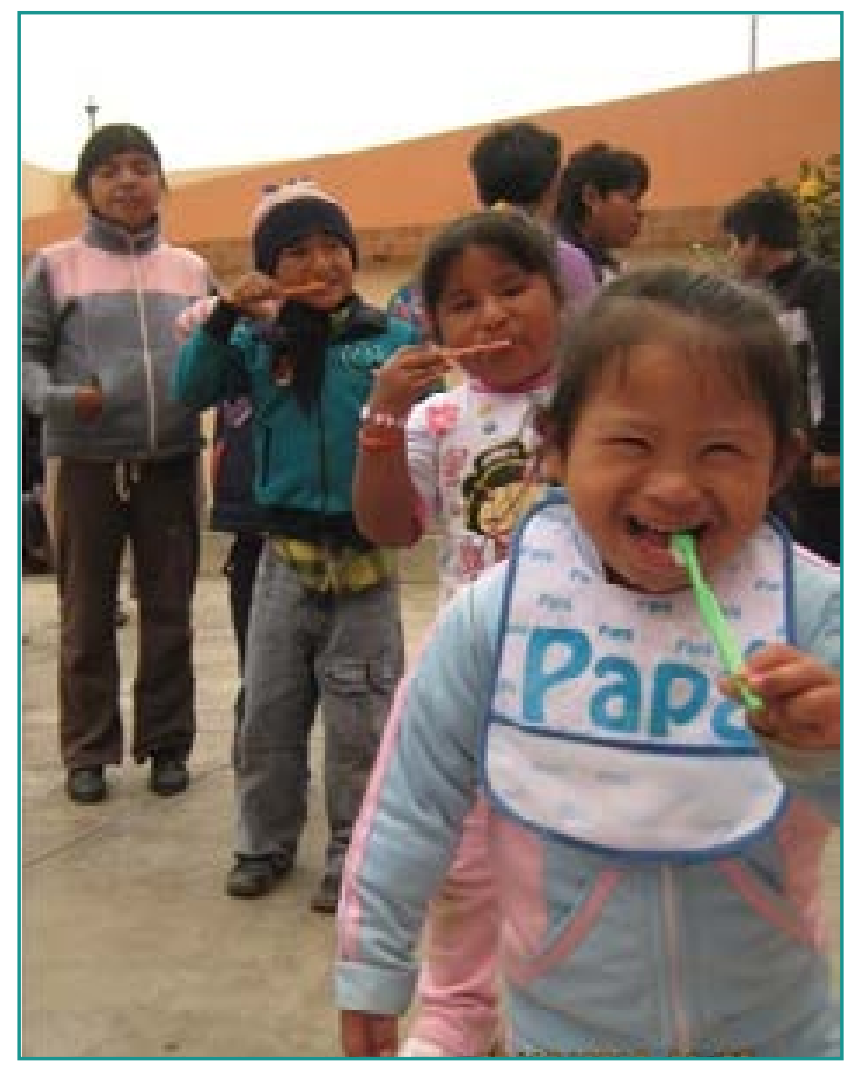

Fotografía 2. Los niños demostrando que ya no solo se cepillaban de forma voluntaria, sino que disfrutaban al hacerlo. 